4 Donaldson C, Wright KG, Maynard AK, Hamill JD, Sutcliffe E. Day hospitals for the elderly: utilisation and performance. Community Med 1987;9:55-61.

5 Peto R. Why do we need systematic overviews of randomized trials? Stat Med 1987;6:233-40.

6 DerSimonian R, Laird N. Meta-analysis in clinical trials. Controlled Clin Trials 1986;7:177-88

7 Woodford-Williams E, McKeon JA, Trotter IS, Watson D, Bushby C. The day hospital in the community care of the elderly. Gerontology Clinic 1962;4:241-56.

8 Weissert W, Wan T, Livieratos B, Katz S. Effects and costs of day-care services for the chronically ill: a randomized experiment. Medical Care $1980 ; 18: 567-84$.

9 Tucker MA, Davison JG, Ogle SJ. Day hospital rehabilitationeffectiveness and cost in the elderly: a randomised controlled trial. $B M J$ $1984 ; 289: 1209-12$

10 Cummings V, Kerner JF, Arones S, Steinbock C. Day hospital service in rehabilitation medicine: an evaluation. Arch Phys Med Rehabil 1985;66: 86-91.

11 Vetter NJ, Smith A, Sastry D, Tinker G. Day hospital pilot study report. Cardiff : Department of Geriatrics, St David's Hospital, 1989.

12 Pitkala K, Winell K, Tilvis RS. Effects of geriatric day hospital care for home care patients. Arch Gerontol Geriatric 1991;suppl 2:51-4.

13 Eagle DJ, Guyatt GH, Patterson C, Turpie I, Sackett B, Singer J. Effectiveness of a geriatric day hospital. Can Med Assoc J 1991;144:699-704.

14 Young JB, Forster A. The Bradford community stroke trial: results at six months. BMJ 1992:304:1085-9.

15 Hedrick SC, Branch LG, eds. Adult day health care evaluation study. Medical Care 1993;31(suppl):SS1-124.

16 Gladman JRF, Lincoln NB, Barer DH. A randomised controlled trial of domiciliary and hospital-based rehabilitation for stroke patients after discharge from hospital. J Neurol Neurosurg Psychiatry 1993;56:960-6.

17 Hui E, Lum CM, Woo J, Or KH, Kay RLC. Outcomes of elderly stroke patients day hospital versus conventional medical management. Stroke 1995;26:1616-9.

18 Burch S, Longbottom J, McKay M, Borland C, Prevost T. A randomised controlled trial of day hospital and day centre therapy. Clin Rehab (in press).

19 Weiler PG, Kim P, Pickard LS. Health care for elderly Americans: evaluation of an adult day health care model. Medical Care 1976;14:700-8.

20 Sherwood S, Morris JN, Ruchlin HS. Alternative paths to long-term care: nursing home, geriatric day hospital, senior center, and domiciliary care options. Am J Public Health 1986:76:38-44.

21 Skellie FA, Mobley GM, Coan RE. Cost-effectiveness of community-based long-term care: current findings of Georgia's alternative health services project. Am J Public Health 1982;72:353-8.

22 Young J, Forster A. Day hospital and home physiotherapy for stroke patients: a comparative cost-effectiveness study. $J R$ Coll Phys Lond $1993 ; 27: 252-7$

23 Gladman J, Whynes D, Lincoln N. Cost comparison of domiciliary and hospital-based stroke rehabilitation. Age Ageing 1994;23:241-5.

24 Egger M, Smith GD, Schneider M, Minder C. Bias in meta-analysis Egger M, Smith GD, Schneider M, Minder C. Bias in
detected by a simple, graphical test. BMJ 1997:315:629-34.

25 Stuck AE, Siu AL, Wieland GD, Adams J, Rubenstein LZ. Comprehensive geriatric assessment: a meta-analysis of controlled trials Lance 1993;342:1032-6.

26 Parker SG, Du X, Bardsley MJ, Goodfellow J, Cooper RG, Cleary R, et al. Measuring outcomes in care of the elderly. $J R$ Coll Phys Lond 1994;28:428-33.

(Accepted 29 January 1999)

\title{
Paralytic poliomyelitis associated with live oral poliomyelitis vaccine in child with HIV infection in Zimbabwe: case report
}

Inam Chitsike, Ralph van Furth

\begin{abstract}
Objective To describe a complication of oral vaccination with live, attenuated poliomyelitis virus in a child infected with HIV.

Design Case report.

Setting Teaching hospital in Harare, Zimbabwe.

Subjects A boy of 41/2 years and his mother.

Main outcome measures Results of clinical and

laboratory investigations.

Results Two weeks after receiving the second dose of oral poliomyelitis vaccine during national

immunisation days the child developed paralysis of the right leg. He had a high titre of antibodies against poliovirus type 2, as well as antibodies against HIV-1, a low CD4 count, a ratio of CD4 to CD8 count of 0.47 , and hypergammaglobulinaemia. He did not have any antibodies against diphtheria, tetanus, or poliovirus types 1 and 3 , although he had been given diphtheria, tetanus, and pertussis and oral polio vaccines during his first year and a booster of the diphtheria, tetanus, and pertussis vaccine at 24 months. He had no clinical symptoms of AIDS, but his mother had AIDS and tuberculosis.

Conclusion Paralytic poliomyelitis in this child with HIV infection was caused by poliovirus type 2 after oral poliomyelitis vaccine.
\end{abstract}

\section{Introduction}

The expanded immunisation programme in Zimbabwe started in 1981 and has a coverage of around 85\% in most areas of the country. ${ }^{1}$ The vaccination schedule is three doses of trivalent oral, live attenuated, poliomyelitis vaccine and diphtheria, tetanus, and pertussis vaccine at 3,4 , and 5 months of age, with a booster of diphtheria, tetanus, and pertussis vaccine at 18 months. In line with the World Health Organisation's goal of eradicating poliomyelitis by $2000,{ }^{2}$ children under 5 years old in Zimbabwe received two doses of oral vaccine, regardless of their vaccination history, during the national immunisation days in $1996 .{ }^{3}$ Most children infected with HIV live in developing countries, so the influence of HIV infection on vaccination against poliomyelitis is relevant. We describe a case of paralytic poliomyelitis in a child with HIV infection after vaccination with oral poliomyelitis vaccine.

\section{Case history}

A boy aged $4 \frac{1}{2} 2$ years who was infected with HIV had been vaccinated with diphtheria, tetanus, and pertussis vaccine and oral poliomyelitis vaccine at the ages of 3 , 4 , and 5 months and had received a booster of diphtheria, tetanus, and pertussis vaccine at 24 months. On the national immunisation days of 1996 (7 August and 29 September) he received oral poliomyelitis vaccine, and a few days after the second immunisation he developed diarrhoea and fever. Two weeks later he developed weakness in his right leg. He was seen at a local primary healthcare clinic, but laboratory tests were not performed.

Three months later, in January 1997, he came to Parirenyatwa Teaching Hospital in Harare because of
Departments of
Paediatrics and
Immunology,
Medical School of
the University of
Zimbabwe, PO Box
A 178, Harare,

BMJ VOLUME 318 27 MARCH 1999 www.bmj.com 
Key messages

- The WHO's goal of eradicating poliomyelitis by 2000 means that children are given live, oral poliomyelitis vaccine during national immunisation days regardless of their vaccination history

- Live vaccines are contraindicated in people who are infected with HIV because of the risk of infection from attenuated micro-organisms

- The incidence of paralytic poliomyelitis associated with vaccination is low in children who are not infected with HIV

- A boy positive for HIV infection developed paralytic poliomyelitis after receiving his second dose of oral poliomyelitis vaccine during national immunisation days in Zimbabwe

- As the benefits of vaccination outweigh the risk of infection with wild poliomyelitis virus, oral poliomyelitis vaccine should continue to be used in countries where HIV infections are endemic

the persistent paralysis. On examination he was well nourished and had flaccid paralysis of his right leg, with diminished tone, power, and reflexes. Magnetic resonance imaging showed appreciable wasting of the muscles of his leg. His lymphocyte count was $2.1 \times 10^{6} / 1$, haemoglobin concentration $108 \mathrm{~g} / \mathrm{l}$, erythrocyte sedimentation rate $61 \mathrm{~mm}$ in the first hour, and total IgG concentration $29.3 \mathrm{~g} / 1$ (normal value for children aged 5-7 years in Harare 8.0 (SD 3.2) g/ $/ \mathrm{l}^{4}$ ). A serum sample contained no antibodies to tetanus or diphtheria toxin (both $<0.01 \mathrm{IU} / \mathrm{ml}$; toxin binding inhibition assay).

Poliovirus and poliovirus antibodies-Poliovirus was not cultured from three stool specimens collected 24 hours apart. Serological tests showed a titre for poliovirus type 2 antibody of 1:1024 but no antibodies to poliovirus types 1 and 3 (both titres <1:8) (microneutralisation test; WHO poliomyelitis reference laboratory, Harare). These titres were confirmed by the Dutch National Institute of Health and the Environment in Bilthoven (titre of poliovirus type 2 antibody 1:512 and no antibodies against poliovirus types 1 and 2). In a second serum sample taken in December 1997 no IgM antibodies against poliovirus types 1, 2, and 3 and no IgG antibodies against poliovirus types 1 and 3 were detected; IgG titre against poliovirus type 2 was 1:16 (microneutralisation test, Dutch National Institute).

$H I V$ antibodies and CD4 counts-Serum antibodies against HIV-1 were detected in two enzyme immunoassays (Sanofi Diagnostics Pasteur, Marnes la Coquette, France, and Abbott, Wiesbaden-Delkenheim, Germany). In January 1997 CD4 count was $733 \times 10^{6} / 1$ (normal count for children aged 1-5 years $>1000 \times 10^{6}$ / 1), CD 8 count $1576 \times 10^{6} / 1$, and the ratio of CD4 to CD8 count 0.47 . In a second serum sample taken in December 1997 the persistence of HIV-1 antibodies was confirmed by enzyme immunoassay (Abbott) and western blotting (Genelabs Diagnostics, Singapore).

Maternal history-During the second half of 1997 the patient's mother became severely ill, having lost much weight. She was treated for tuberculosis for six months in hospital outside Harare; her HIV serology was positive. She also had chronic diarrhoea. According to WHO case definitions, ${ }^{5}$ she had AIDS. She died in August 1998.
Follow up-In February 1999 the child still had severe paralysis of his leg and a pronounced limp. He was admitted because of weight loss. An $x$ ray film showed bilateral hazy infiltration of the lungs and he was treated for tuberculosis. His HIV infection was progressing to AIDS.

\section{Discussion}

The results of physical examination and the presence of antibodies against poliomyelitis virus meet the criteria of the ninth revision of the international classification of diseases (ICD-9) for paralytic poliomyelitis, as the paralysis occurred within 4-30 days after vaccination. ${ }^{1}$ Poliomyelitis was probably caused by the vaccine strain of poliovirus type 2. The presence of HIV antibodies meet the WHO's criteria for confirmed HIV infection, ${ }^{5}$ which was probably acquired perinatally.

Since 1990 no wild type poliovirus has been isolated in Zimbabwe (WHO Poliomyelitis Reference Laboratory, Harare, personal communication). ${ }^{1}$ In the neighbouring country of Namibia, however, an outbreak of poliomyelitis caused by wild type poliovirus type 1 occurred in $1993{ }^{6}$ A review of hospital records during 1990-2 showed that three children under 15 years old developed acute flaccid paralysis in Zimbabwe. ${ }^{1}$ Virus isolation and antibodies were not reported, so the infection may not have been caused by poliovirus. In 1995 acute flaccid paralysis was diagnosed in 39 children in Zimbabwe; poliovirus type 1 was isolated from stool samples in two children aged 5 and 6 years who did not remain paralysed. In 1996 among 20 children with acute flaccid paralysis poliovirus type 2 was isolated from one child aged 1 year who had residual paralysis (WHO, Poliomyelitis Reference Laboratory, Harare, personal communication). The HIV status of these last three children is not known.

Our patient probably had a humoral immune deficiency because after vaccination he did not develop antibodies against diphtheria toxin, tetanus toxin, or poliovirus types 1 and 3 and probably not against poliovirus type 2 after oral vaccination during infancy. This deficiency could be due to an altered immune state from his perinatally acquired HIV-1 infection. Interestingly, after infection with the vaccine strain he made antibodies against poliovirus type 2. Children infected with HIV-1 develop significantly less antibody than uninfected children in response to diphtheria toxoid, tetanus toxoid, and oral poliomyelitis vaccine. ${ }^{78}$ Adults with HIV infection and low CD4 counts also form less antibody than do those with CD4 counts $>300 \times 10^{6} / 1$ in response to diphtheria toxoid, tetanus toxoid, and inactivated poliomyelitis vaccine. ${ }^{9}$

In our patient humoral immune deficiency, especially the absence of polio antibodies, might have contributed to the dissemination of the virus after vaccination with oral vaccine during the national immunisation days, thus causing infection of the central nervous system. The prevalence of paralytic poliomyelitis associated with oral poliomyelitis vaccine is low: one case per 2.5 million doses. In addition, $18 \%$ of those who developed this complication were immunocompromised, predominantly young children with hypogammaglobulinaemia or agammaglobulinaemia. ${ }^{310}{ }^{11}$ Children infected with HIV are potentially at risk of this and other complications after vaccination 
with live attenuated micro-organisms. ${ }^{378}$ We believe that only one case of paralytic paralysis associated with oral poliomyelitis vaccine has been reported in a child with HIV infection from Romania. ${ }^{12}$ Thus oral poliomyelitis vaccine seems to be safe when given during the first year of life. ${ }^{1710}{ }^{13}$ To our knowledge, our case is the first report of poliomyelitis associated with poliomyelitis vaccination in a child infected with HIV from Africa. In countries where HIV infection is endemic and the risk of infection with wild type poliomyelitis virus is high, the benefits of immunisation outweigh the apparently low risk of paralysis due to vaccination with oral poliomyelitis vaccine.

We thank Dr E N Sibanda, Department of Immunology, University of Zimbabwe, Harare, for his help.

Contributors: IC and RvF are both responsible for all aspects

of this paper and are guarantors for the study.

Funding: None.

Competing interests: None declared.

1 Anonymous. Acute flaccid paralysis surveillance, 1992, Zimbabwe. Wkl Epidemiol Rec 1993;68:264-6.

2 Wright PF, Kim-Farley RJ, de Quadros CA, Robertson SE, Scott RM, Ward NA, et al. Strategies for the global eradication of poliomyelitis by the year 2000. N Engl J Med 1992;325:1774-9.
3 Robertson SE, The immunological basis for immunization. VI. Poliomyelitis. WHO/EPI/GEN 1993;16:1-24. (Available from WHO Geneva.)

4 Gomo Z, Sikunda D The immunoglobulin levels in infants attending a routine health clinic at Mbare polyclinic. Central African Journal of Medicine 1992;38:281-6.

5 Anonymous. WHO case definitions for AIDS surveillance in adults and adolescents Wkly Fpidemiol Rec 1994:69:273-5

6 Van Niekerk ABW, Schoub BD, Chezzi C, Blackburn NK, Vries JB, Baard J. Outbreak of poliomyelitis in Namibia. Lancet 1994;343:51.

7 Ryder RW, Oxtoby MJ, Mvula M, Batter V, Baende E, Nsa W, et al. Safety and immunogenicity of bacille Calmette-Guérin, diphtheria-tetanuspertussis, and oral polio vaccines in newborn children in Zaire infected with human immunodeficiency virus type 1.J Pediatr 1993;122:697-702

8 Barbi M, Biffi MR, Binda S, Clerici-Schoeller M, Ferraris G, Luraschi C, a Im al. Immunzation in children with HIV seropostivity at binth: antibor response to polio vaccine and tetanus toxoid. AIDS 1992;6:1465-9.

9 Kroon FP, van Dissel JT, Labadie J, van Loon AM, van Furth R. Antibody response to diphtheria, tetanus, and poliomyelitis vaccines in relation to the number of CD4 + T lymphocytes in adults infected with human immunodeficiency virus. Clin Infect Dis 1995;21:1197-203.

10 Nikowane BM, Wassilak SGF, Orenstein WA, Bart KJ, Schonberger LB, Hinman AR, et al. Vaccine-associated paralytic poliomyelitis: 1973 through 1984. JAMA 1987;257:1335-40.

11 Strebel PM, Sutter RW, Cochi SL, Biellik RJ, Brink EW, Kew OM, et al. Epidemiology of poliomyelitis in the United States one decade after the last reported case of indigenous wild virus-assosiated disease Clin Infect Dis $1992 ; 14: 568-79$

12 Ion-Nedelcu N, Dobrescu A, Strebel PM, Sutter RW. Vaccine-associated paralytic poliomyelitis and HIV infection. Lancet 1994;343:51-2.

13 McLaughlin M, Thomas P, Onorato I, Oleske J, Nicholas S, Krasinski K, et al. Live virus vaccines in human immunodeficiency virus-infected children: a retrospective survey. Pediatrics 1988;82:229-33.

(Accepted 16 April 1998)

\title{
Postcodes as useful markers of social class: population based study in 26000 British households
}

\author{
John Danesh, Simon Gault, Jo Semmence, Paul Appleby, Richard Peto
}

Markers of poverty or of low social class are associated with many diseases and potential causes of disease, but medical studies often fail to record sufficient information on socioeconomic status. ${ }^{1}$ Postcodes of individuals are, however, often available in Britain, and commercial software exists that estimates household income from the postcode alone. We assessed how informative postcode income estimates are, either about reported household income or about other characteristics related to social class in a large, population based survey of British residents.

\section{Methods and results}

The family resources survey involves personal interviews with members of private households in England, Scotland, and Wales selected by stratified clustered probability sample. ${ }^{2}$ During 1995-6, 26445 (70\%) of 37712 eligible households gave answers to questions on socioeconomic characteristics. Reported weekly household income was taken as the sum of all sources of pretaxation income (excluding housing benefit) reported by household members. During 1985 to 1993 members of 11 million households, or about half of all households in Britain, provided information to a marketing company about annual income and gave a complete address that included a full postcode- - that is, 6 or 7 characters.

This information was used to produce commercial software that estimates household incomes from postcodes. After adjustments for regional variation and for inflation in reported income levels, the pretaxation incomes of at least six households were used to calculate a weighted average income for that postcode When there were fewer than six responses, the income information was combined with the data for respondents with neighbouring postcodes until a reliable estimate could be made. Parts of this database are updated annually. We compared household income estimates obtained by FIND (a commercially available software program) with information reported in the family resources survey. Matching of the data was carried out at the Office for National Statistics. The investigators in this study were provided with columns of numerical data without any personal identifiers.

The overall correlation coefficient between postcode estimates and reported values of weekly household income for 26282 individuals was moderate $(0.40,99 \%$ confidence interval 0.39 to 0.42 ; $2 \mathrm{P}<0.0001)$. When households were ranked in three equal sized groups on the basis of postcode income estimates, there were substantial and highly significant differences in reported weekly income, duration of education, home ownership, membership of higher social classes, and access to various consumer goods $(2 \mathrm{P}<0.0001$ for each) (see table).

\section{Comment}

Postcode income estimates are easily available in Britain and can be useful markers of social class. As UK postcodes are usually shared by only 15 to 20 households, ${ }^{3}$ these estimates should more accurately predict the social class of individuals than can more
Clinical Trial Service Unit and Epidemiological Studies Unit, University of Oxford, Radcliffe Infirmary, Oxford OX2 6HE

John Danesh, Merton College junior research fellow Richard Peto professor of medical statistics and epidemiology

Family Resources Survey, Department of Social Security, London

WC2N 6HT

Simon Gault, assistant statistician Jo Semmence, statistician

Imperial Cancer Research Fund Cancer

Epidemiology Unit Radcliffe Infirmary, Oxford OX2 6HE

Paul Appleby, research officer

Correspondence: Dr Danesh

john.danesh@

balliol.ox.ac.uk

BMJ 1999;318:843-5 